\title{
Effect of Test Velocity on the Specific Energy Absorption under Progressive Crushing of Composite Tubes
}

\author{
Grażyna Ryzińska ${ }^{* *}$, Roman Gieleta ${ }^{2}$ \\ 1 Rzeszow University of Technology, Faculty of Mechanical Engineering and Aeronautics, al. Powstańców \\ Warszawy 12, 35-959 Rzeszow, Poland, grar@prz.edu.pl \\ 2 Military University of Technology, ul. gen. Sylwestra Kaliskiego 2, 00-908 Warsaw 46, Poland \\ * Corresponding author's e-mail: grar@prz.edu.pl
}

\begin{abstract}
The paper presents the results of the compression tests for carbon-epoxy composites in order to assess the amount of energy absorbed depending on the process velocity and content of axial fibres. Two types of prepreg (UD $200 \mathrm{~g} / \mathrm{m}^{2}$ and woven $160 \mathrm{~g} / \mathrm{m}^{2}$ ) were used to prepare the specimens with a diameter of $20 \mathrm{~mm}$ and a height of $34 \mathrm{~mm}$. The specimens were subjected to compression under various speed conditions (static, dynamic and SHPB tests). The calculated specific energy absorption values showed a $50-60 \%$ decrease with increasing process velocity and depending on the type of specimens architecture. The highest energy values were absorbed by the specimens with the highest share of axial fibres in the sample.
\end{abstract}

Keywords: CFRP, energy absorption, progressive crushing, crashworthiness, SHPB, velocity

\section{INTRODUCTION}

Composite materials (reinforced plastics, ceramic matrix composites, metal matrix composites) are increasingly often used in modern construction solutions [1-5]. The aviation, automotive and railway sectors are constantly looking for new solutions for the production of increasingly lighter vehicles, but equally important goal is meeting high safety standards. Therefore, composite products are already widely used in this area as structural elements [1], but they can also be used as energy absorbing elements.

Research shows that among various composite materials, the carbon-fibre reinforced composites are the most efficient as impact absorbing elements. In addition, they are distinguished by excellent stiffness and low weight [2, 6-18].

However, to enable effective work of composite elements under real conditions and facilitate designing, the detailed knowledge of factors affecting the behavior of a composite element absorbing energy is necessary.
The test velocity is one of the important factors significantly modifying the behavior of the element during the composite crushing process [19]. This is crucial especially in the design of this type of elements and their subsequent work.

The impact of the test velocity on the specific energy absorption (SEA) in the process of tube crushing is not conclusive (Table 1). There are studies showing an increase and a decrease of SEA depending on the velocity of the process. For example, in [20], an increase in the force of progressive crushing of composite tubes by $10 \%$ for a velocity of $900 \mathrm{~mm} / \mathrm{min}$, which resulted in an increase of SEA by $12 \%$ compared to the quasi-static test $(\mathrm{v}=5 \mathrm{~mm} / \mathrm{min})$ was demonstrated. In [10], it was found that the tubes with an increasing axial fiber content absorb more energy for the test speed of $2 \mathrm{~m} / \mathrm{s}$, while for a lower speed of $0.004 \mathrm{~m} / \mathrm{s}$, the relationship increases and then decreases. Farley [8] showed that for composite specimens (carbon fiber - epoxy resin) in the range of tested 
Table. 1. Exemplary data showing reduction or increase of SEA depending on the test velocity

\begin{tabular}{|c|l|c|c|}
\hline References & \multicolumn{1}{|c|}{ Specimen type } & Velocity, m/s & SEA change \\
\hline$[8]$ & CF/epoxy, tube $\circ[ \pm 75]_{3}$ & $1 \mathrm{e}-4 \div 12$ & $+35 \%$ \\
\hline$[21]$ & CF/epoxy, tube $\circ[0, \pm 75]_{2}$ and $[0, \pm 45]_{2}$ & $2 \mathrm{e}-6 \div 4 \mathrm{e}-5$ & $0 \%$ \\
\hline$[22,23]$ & GF/epoxy, tube $\square$, cone & $2 \mathrm{e}-4 \div 8$ & $-15 \%-+20 \%$ \\
\hline$[17]$ & CF/epoxy, tube $\circ$ & $0.001 \div 12$ & $-20 \%$ \\
\hline$[20]$ & CF/epoxy, tube $\circ[0, \pm 90]$ & $8.3 \mathrm{e}-5 \div 0.015$ & $+12 \%$ \\
\hline$[24]$ & GF/CF/polyester, tube $\square$ & $8.3 \mathrm{e}-5 \div 0.008$ & $+9 \%$ \\
\hline$[25]$ & CF/epoxy $\left[(0, \pm 90)_{2} / 0 /(90, \pm 0)_{2}\right]$, DLR & $0,001 \div 2$ & $-22 \%$ \\
\hline$[26]$ & CF/epoxy, plate & $2 \mathrm{e}-5 \div 5.2$ & $-19 \%$ \\
\hline$[27]$ & CF/epoxy, tube $\circ[0, \pm 90]$ & $0.0003 \div 6.7$ & $-10 \% \div-20 \%$ \\
\hline
\end{tabular}

velocity of $0.01 \mathrm{~m} / \mathrm{s}-12 \mathrm{~m} / \mathrm{s}$, SEA is a weak function of velocity, and when the orientation angle of the layer increases from $45^{\circ}$ to $75^{\circ}$, this effect is stronger.

Works $[28,29]$ show the results of the crushing tests for the square tubes and cones made of glass - epoxy composite in the speed range of $0.0002 \mathrm{~m} / \mathrm{s}-8 \mathrm{~m} / \mathrm{s}$. It was shown that the change in the value of SEA was in the range from $-15 \%$ to $+20 \%$, which is explained by the variable coefficient of friction depending on the test velocity. A decrease in SEA for carbon - epoxy composite in the process velocity range $0.001 \mathrm{~m} / \mathrm{s}-12 \mathrm{~m} / \mathrm{s}$ was shown in $[17,30]$, this phenomenon is explained by the reduction of the friction coefficient under dynamic conditions, a change in the mechanical properties of the matrix and a change in the crushing mechanism.

In work [25] the attention was paid to the phenomenon of two types of material reactions depending on the process velocity: Global Splaying Failure crush mode (GSF) for low velocity and Local Fragmentation Failure crush mode (LFF) for dynamic conditions.

The research indicates the problems with testing composite materials for impact energy absorption elements. Among the research methods used so far, the results of tube testing are definitely the most useful, especially with regard to the fact that the largest amounts of energy per unit of mass are absorbed by the tube-shaped elements with an appropriate ratio of wall thickness to diameter $(t / D)$, which is in the range of $0.025-0.066$ [31]. Therefore, the studies of this type of structures should be carried out using the tubes with a constant $t / D$ ratio, additionally with the use of a trigger that corrects the initial forces as well as with the plug initiator which causes the progressive process. These test conditions are the closest to the real working conditions of such an element and are easiest to compare with other studies.

Another factor that affects the amount of energy absorbed is a type and architecture of reinforcement [32]. The advantage of long fibers and fabrics over mats and short fibers is evident [33]. In the study [27] the impact of architecture on SEA for a set of two materials (the area weight of $200 \mathrm{~g} / \mathrm{m}^{2}$ and $204 \mathrm{~g} / \mathrm{m}^{2}$ ) was examined; however, the influence of a type and architecture of reinforcement on SEA still requires confirmation for other materials.

\section{Definitions}

The total amount of energy absorbed by the structure $\left(\mathrm{E}_{\text {tot }}\right)$ is defined as:

$$
E_{\text {tot }}=\int_{0}^{l} P d l
$$

where: $E_{\text {tot }}$ - energy absorbed,

$P$ - force,

I-stroke,

Specific energy absorbed (SEA):

$$
S E A=E_{t o t} / \rho A l
$$

where: $\rho$-density of the tube,

$A$ - specimen cross-sectional area,

In order to determine the impact of structure architecture on energy absorption, a new coefficient AFMF (Axial Fibre Mass Fraction) was introduced, which determines the mass fraction of axial fibres in relation to the total mass of all fibres in the sample. A description can be found in [27]:

$$
A F M F=\frac{M_{a x f}}{M_{f}}
$$




\section{MATERIALS AND SPECIMENS}

In the presented experimental study, the composite samples with an internal diameter of $20.0 \mathrm{~mm}$ and a height of $34.0 \mathrm{~mm}$ were manufactured. Two kinds of prepreg from Impregnatex Compositi were used to obtain a different architecture, namely $3 \mathrm{k}$ woven fabric (WF) and $3 \mathrm{k}$ unidirectional (UD). The mechanical properties of the prepregs used were determined experimentally and are shown in Table 2.

The specimens were made by hand layup suitable layers of prepreg on a $0.5 \mathrm{~m}$ long Teflon core. Then, they were cured in an autoclave at $130^{\circ} \mathrm{C}$ for 3 hours. A set of $0.5 \mathrm{~m}$ long tubes was made, which were then cut to $34 \mathrm{~mm}$ in length (Fig. 1). The plug initiator with an external radius $\mathrm{r}=1 \mathrm{~mm}$ was used in experimental work, as shown in Figure 2.

The specimens were designed to differ in AFMF values. This effect was obtained by using a different number of UD layers in relation to the number of WF layers, as shown in Figure 3.

\section{Quasi static test}

The tests under quasi-static conditions were conducted using Zwick uniaxial testing machine with the capacity of $30 \mathrm{kN}$. General view of quasi -static test set up is shown in Figure 4. Three specimens were tested for each case at a constant process velocity $\mathrm{v}=0.0003 \mathrm{~m} / \mathrm{s}$. In the quasistatic test, a displacement of $25 \mathrm{~mm}$ was applied.
As a result of the conducted experimental tests, the force-displacement plots were obtained for the all tested specimen variants (Fig. 5). In Figure 5b, it is evident that there is very little scatter in the force-displacement curves for all three specimens with the same AFMF tested under quasi-static conditions. The quality and consistency of specimens production allowed obtaining reproducible results. The view of specimens after the test is shown in Figure 6.

\section{Dynamic tests}

In the part concerning dynamic tests, three samples were tested for each case. The tests were carried out using a gravity hammer (Fig. 7). Depending on the configuration of the layers (AFMF), the samples absorbed a different amount of energy in the process, in some cases forcing adjustment of the height of fall and the weight of the hammer to the type of the sample. The collected data allowed gathering information not only on the energy absorbed (SEA), but also on the behavior of the test specimen during the process (initial force $\mathrm{P}_{\text {max }}$, steady state force $\mathrm{P}_{\mathrm{i}}$, displacement). As a result of the conducted experimental tests, force-displacement plots were obtained for all the tested specimens (Fig. 8). The representative view of specimens after a dynamic crush test is shown in Figure 9.

While analyzing the results of tests carried out under dynamic conditions, particular attention should be paid to the force - displacement

Table 2. The mechanical properties of used materials

\begin{tabular}{|c|c|c|}
\hline Specification & 160 3k (WF) plain woven & 200 3k (UD) unidirectional \\
\hline Ply thickness, mm & 0.23 & 0.23 \\
\hline Dry areal density, $\mathrm{g} / \mathrm{m}^{2}$ & 160 & 200 \\
\hline Axial modulus $\mathrm{E}_{1 \mathrm{t},} \mathrm{MPa}$ & 52748.1 & 104634.0 \\
\hline Transverse modulus $\mathrm{E}_{2 \mathrm{t},} \mathrm{MPa}$ & 51134.8 & 9914.0 \\
\hline Strength $\sigma_{1 \mathrm{t}}, \mathrm{MPa}$ & 500,8 & 1723,0 \\
\hline Strength $\sigma_{2 \mathrm{t}}, \mathrm{MPa}$ & 439,3 & 78,6 \\
\hline Failure strain $\varepsilon_{1 \mathrm{t},} \%$ & 1,05 & 1,48 \\
\hline Failure strain $\varepsilon_{2 t} \%$ & 0,82 & 0,81 \\
\hline Axial modulus $\mathrm{E}_{1 \mathrm{c}}, \mathrm{MPa}$ & 51693.5 & 96983 \\
\hline Transverse modulus $\mathrm{E}_{2 \mathrm{c},} \mathrm{MPa}$ & 51153.5 & 9489.1 \\
\hline Strength $\sigma_{1 \mathrm{c}}, \mathrm{MPa}$ & 308.8 & 534.8 \\
\hline Strength $\sigma_{2 \mathrm{c}}, \mathrm{MPa}$ & 309.2 & 96.4 \\
\hline Failure strain $\varepsilon_{1 \mathrm{c},} \%$ & 0.0071 & 0.0055 \\
\hline Failure strain $\varepsilon_{2 \mathrm{c},} \%$ & 0.0090 & 0.0281 \\
\hline$v_{12 c}$ & 0.0739 & 0.2643 \\
\hline $\mathrm{v}_{21 \mathrm{c}}$ & 0.0511 & 0.0178 \\
\hline
\end{tabular}




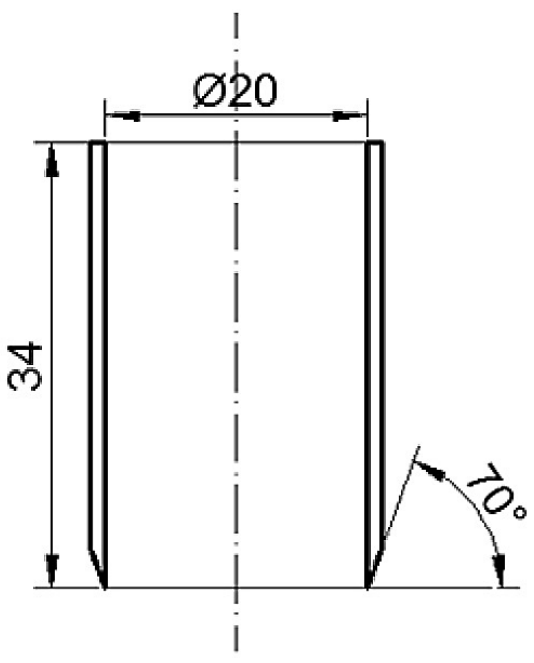

Fig. 1. Tube specimen geometry

characteristics, which are less uniform than in the case of quasi-static tests. The appearance of the specimens after dynamic tests (Fig. 9) indicates the presence of a splaying mechanism in the case of a higher AFMF value. As the proportion of axial fibers decreases in the specimens, more intense fibers breaking can be observed, which may indicate the predominance of the fragmentation mechanism.

The axial cracking of the composite significantly contributes to the energy absorption. In the photographs of the samples after compression, a various number of axial cracks is visible. The greatest number of them can be observed in

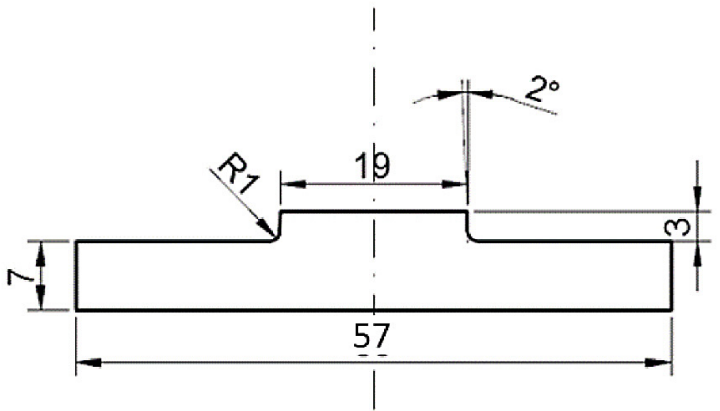

Fig. 2. Plug initiator used in experimental work

the case of samples containing only axial fibers $(A F M F=1)$. This resulted from easy separation of the composite fibers in the circumferential direction due to the absence of limiting hoop fibers. The axial cracks in the absence of hoop fibers do not seem to be a mechanism that has a significant impact on the energy absorption. However, this process is very intense, and the number of axial cracks is high, which means that this share in the overall energy absorption calculation is gaining importance.

\section{Split Hopkinson Pressure Bar test}

In the studies with the use of SHPB, the samples were halved in relation to the specimens used in the quasi-static and dynamic tests due to the specific character of the measurement. The height of the specimens used in the SHPB tests was $18.0 \mathrm{~mm}$.

b)

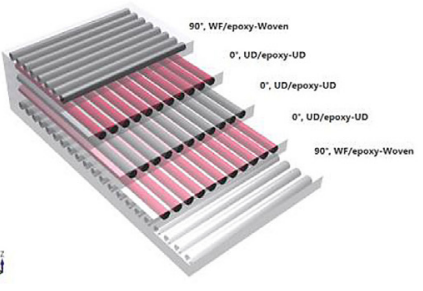

d)

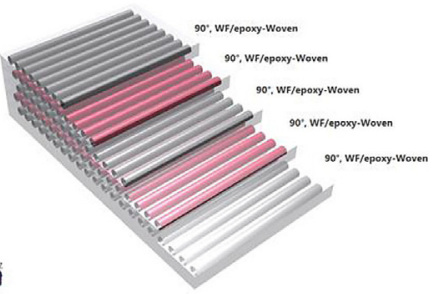

$x^{2}$
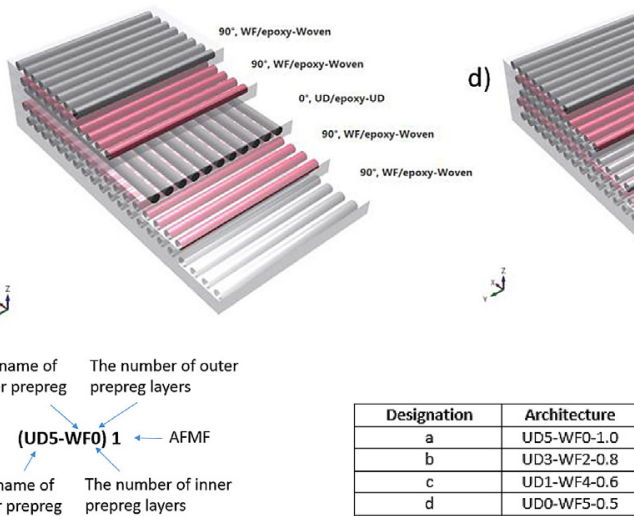

Fig. 3. Specimen architecture and designation 


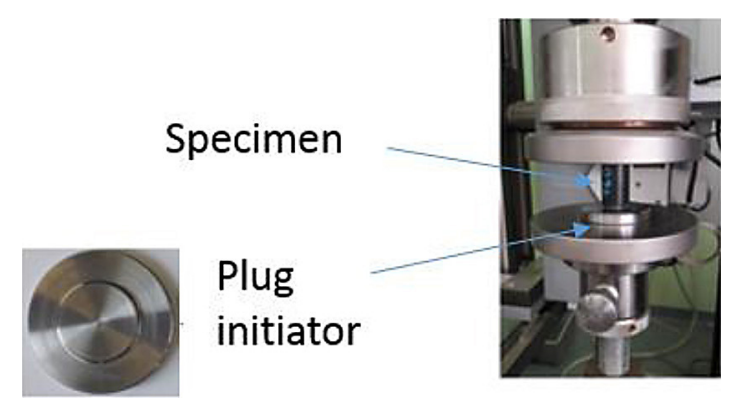

Fig. 4. Quasi-static test set-up, $v=20 \mathrm{~mm} / \mathrm{min}(\mathrm{QS})$
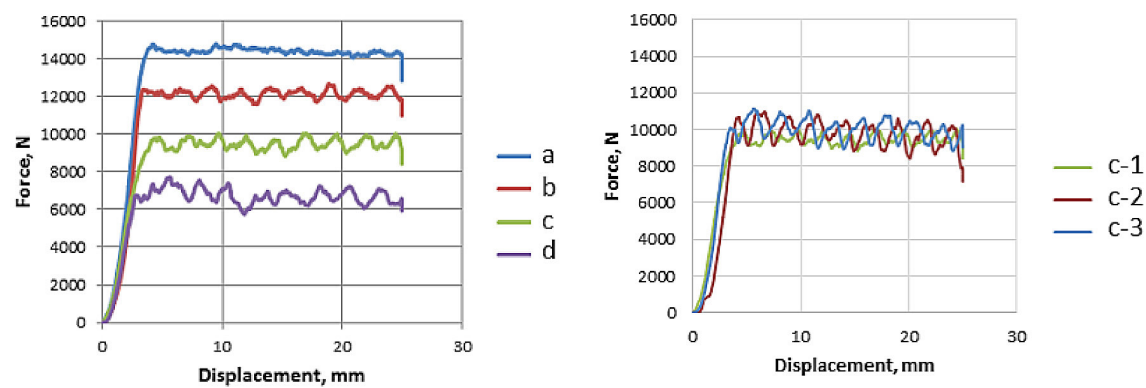

Fig. 5. Force-displacement plots for the quasi-static tests (QS); a) results for representative specimens for different AFMF; b) results for three specimens with the same AFMF

a)

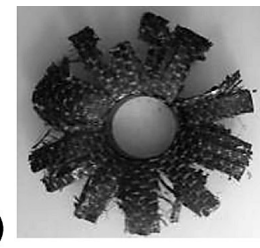

b)

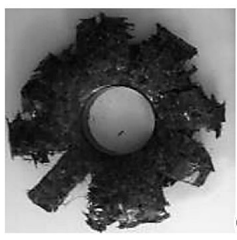

c)

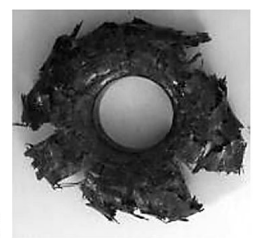

d)

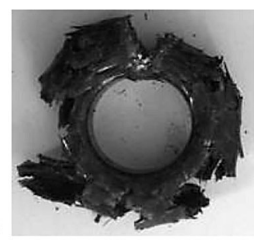

Fig. 6. View of representative specimens after crush test; quasi-static test $20 \mathrm{~mm} / \mathrm{min}(\mathrm{QS})$; a) $\mathrm{AFMF}=1$; b) $\mathrm{AFMF}=0.8$; ) $\mathrm{AFMF}=0.6$; d) $\mathrm{AFMF}=0.5$

The experimental compression tests at high strain rates were performed on the conventional SHPB apparatus (Fig. 10). A description of the SHPB used is contained in [32]. The details of this technique are included in $[34,35]$.

During the experimental investigations, the striker velocities were about $21 \mathrm{~m} / \mathrm{s}$. A pulse shaping technique was used to shape the profile of the incident pulse. Copper disks with a diameter $\mathrm{D}_{\mathrm{s}}=6 \mathrm{~mm}$ and thickness $\mathrm{L}_{\mathrm{s}}=1 \mathrm{~mm}$ were used as pulse shapers. The shape of one end of the transmission bar was the same as a plug initiator in quasi-static and dynamic tests (Fig. 11). The strain gauge signals prepared for calculations of specimen shortening were shown in Figure 12.

The calculated quantities were used to prepare the force-displacement diagrams at high strain rate tests. The force-displacement curves for the specimens with different AFMF are shown in Figure 13. The representative view of crushed samples is shown in Figure 14.

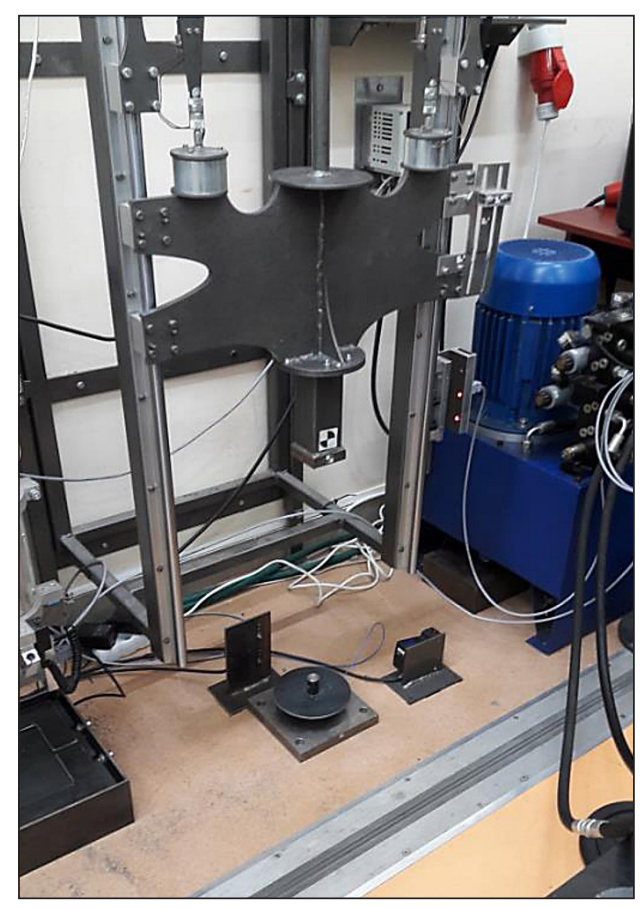

Fig. 7. Gravity hammer used in dynamic tests (D) 

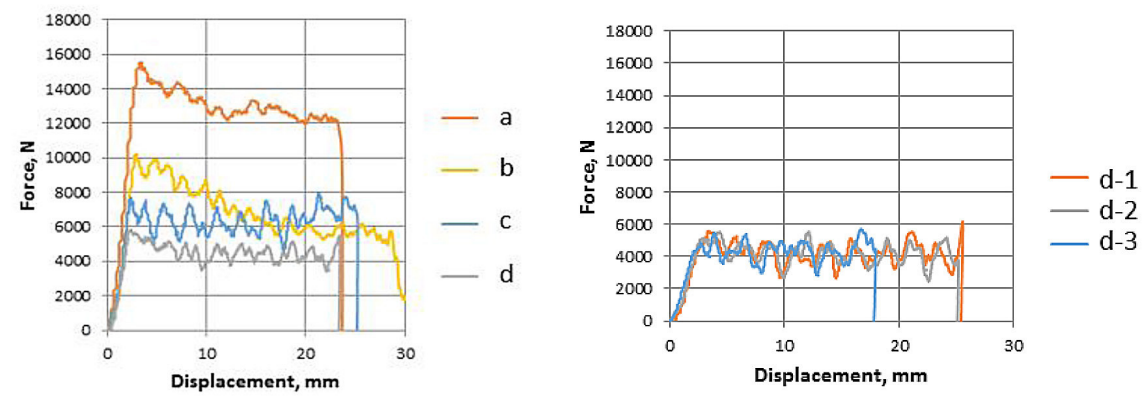

Fig. 8. Force - displacement plots for dynamic tests (D); a) results for representative specimens for different AFMF, b) results for three specimens with the same AFMF

a)

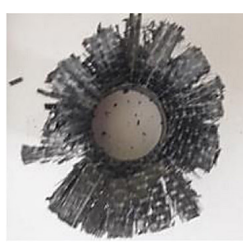

b)

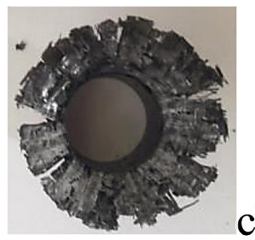

c)

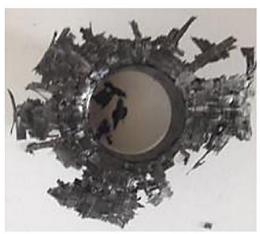

d)

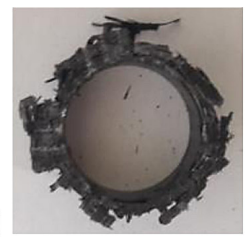

Fig. 9. View of representative crushed specimens; dynamic test (D); a) $\mathrm{AFMF}=1$; b) $\mathrm{AFMF}=0.8$; ) $\mathrm{AFMF}=0.6$; $) \mathrm{AFMF}=0.5$

The results of the tests using SHPB allowed obtaining the force-displacement plots in a much lower range than in the case of the tests under quasi-static and dynamic conditions. Therefore, the conclusions drawn from this test are limited. However, the maximum force was achieved. The steady state was not obtained and therefore $\mathrm{P}_{\mathrm{i}}$ value was not determined.

The obtained SEA values, similarly as in the tests with lower velocity, increase along with the share of axial fibers in the sample. This trend is evident for all crushing tests of the composite specimens included in this study. The appearance of samples after testing with SHPB indicates the occurrence of the splaying mechanism to a significantly lesser extent than in the case of the tests with a lower process velocity. However, the splaying mechanism can still be observed to be more significant in the case of a larger AFMF. As AFMF decreases, the fragmentation mechanism gains the advantage.

\section{Influence of test velocity on SEA}

In order to evaluate the impact of the test velocity on the effect of the absorbed amount of energy, the SEA - AFMF plots for the same material and a different test velocity were done. The crushing results under quasi-static conditions, dynamic conditions and using SHPB were compared (Fig. 15). On the basis of the conducted experimental tests, it can be clearly stated that an increase of the test velocity for all tested types of samples causes a decrease in the value of the absorbed energy (SEA) (Table 3).

\section{CONCLUSIONS}

The results of the systematic tests of CFRP composite materials (with epoxy resin IMP 530 as a matrix), based on Impregnatex Compositi prepregs were presented in this work. The composites with a given geometry were subjected to axial crushing tests with three different test velocities: $20 \mathrm{~mm} / \mathrm{min}, 5 \mathrm{~m} / \mathrm{s}$ and $21 \mathrm{~m} / \mathrm{s}$ mainly to assess an influence of the share of axial fibers and a process velocity on the energy absorption effect in the progressive crushing process. The

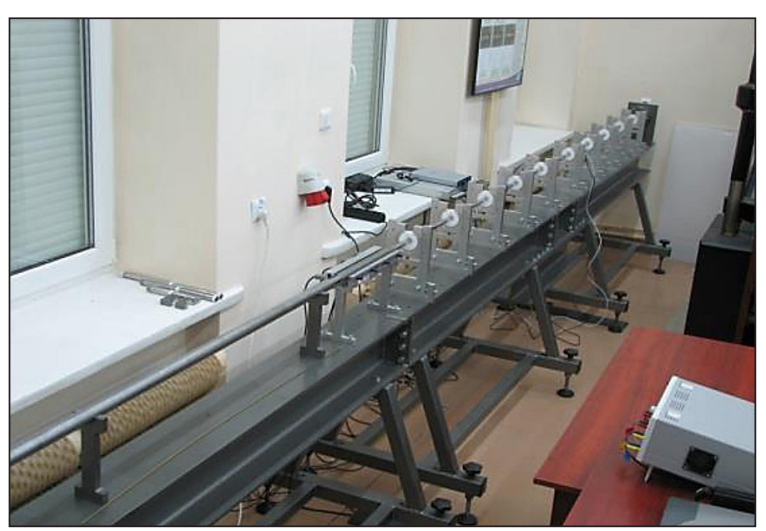

Fig. 10. General view of the Split Hopkinson Pressure Bar apparatus [32] 

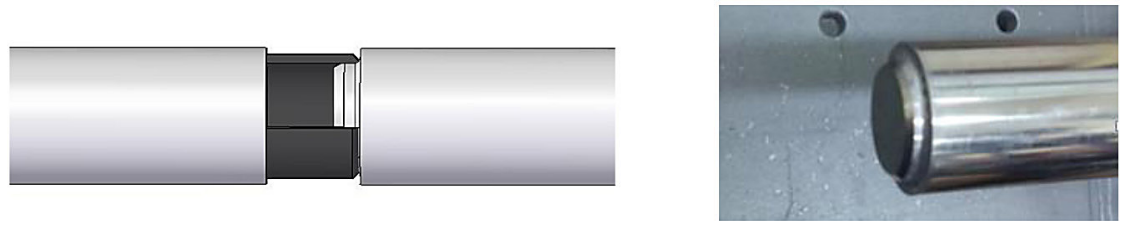

Fig. 11. Scheme of the chamfered specimen (sectional view) and view of the modified transmission bar

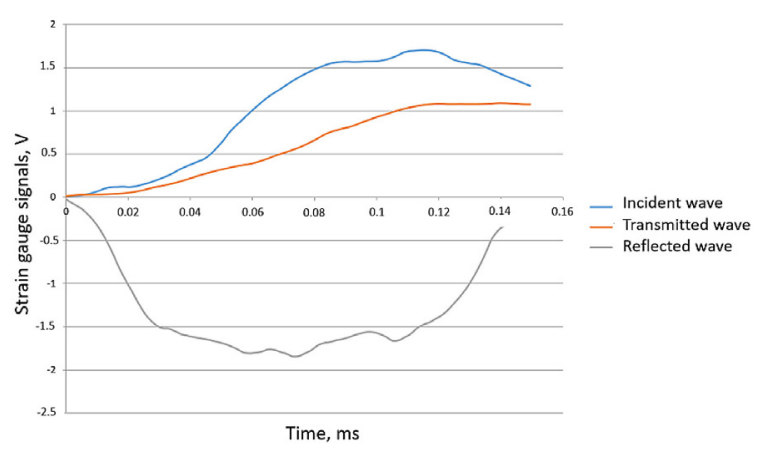

Fig.12. Strain gauge signals prepared for calculations of specimen shortening, force and strain rate

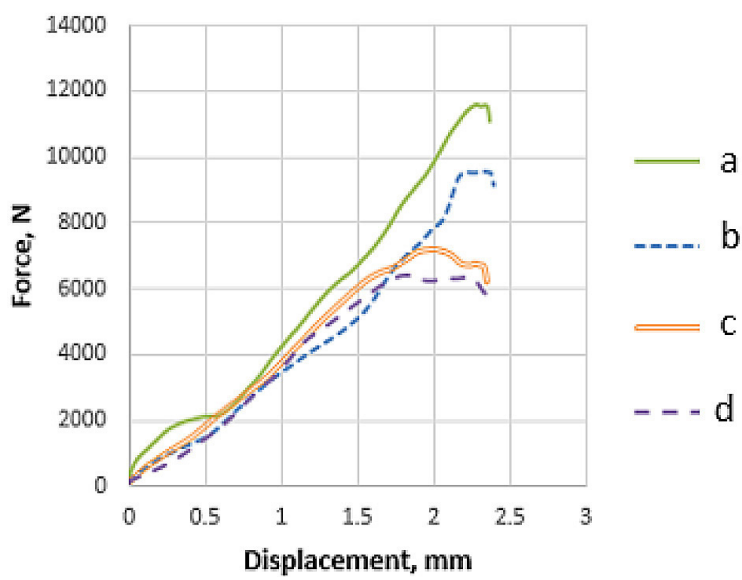

Fig. 13. Force-displacement plots, SHPB tests; results for representative specimens of different AFMF performed research allows to formulation of the following conclusions:

- The content of axial fibers significantly affects the maximum force, steady state force and, as a consequence, the amount of energy absorbed during crushing of composite tubes. This influence is evident for the studied velocity range from $20 \mathrm{~mm} / \mathrm{min}$ to $21 \mathrm{~m} / \mathrm{s}$. The increase in AFMF causes an increase in the amount of energy absorbed in all the investigated cases.

- For $\mathrm{AFMF}=0.5$ a test velocity increasing from $20 \mathrm{~mm} / \mathrm{min}$ to $21 \mathrm{~m} / \mathrm{s}$ results in a reduction in SEA of about $49.2 \%$.

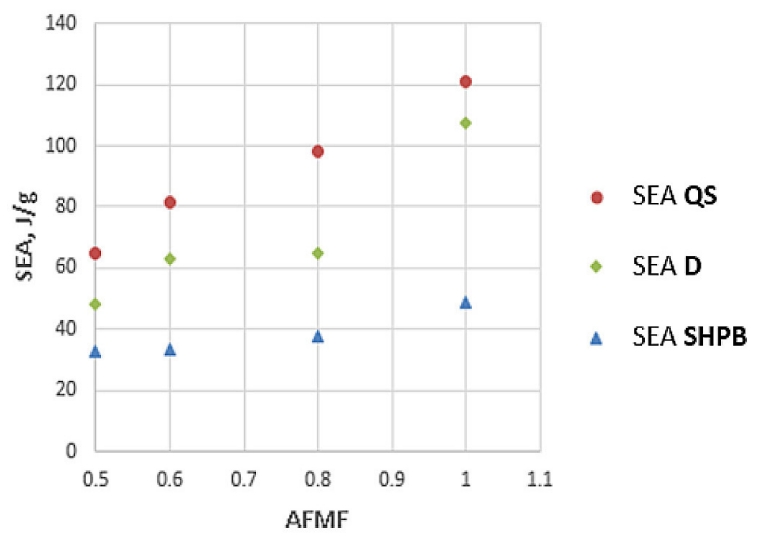

Fig. 15. Dependence between SEA and AFMF. Results for quasi static test (QS), dynamic test (D) and SHPB test

Table 3. Experimental results for tests performed with three different velocity conditions

\begin{tabular}{|c|c|c|c|c|c|}
\hline Specification & AFMF & 1 & 0.8 & 0.6 & 0.5 \\
\hline \multirow{5}{*}{ QS } & No of specimen & 3 & 3 & 3 & 3 \\
\hline & Average velocity, m/s & 0.0003 & 0.0003 & 0.0003 & 0.0003 \\
\hline & SEA $_{Q S}$ & $121 \pm 4$ & $98 \pm 6$ & $81 \pm 9$ & $65 \pm 8$ \\
\hline & $\mathrm{CFE}_{\text {QS }}$ & $0.93 \pm 0.03$ & $0.90 \pm 0.1$ & $0.93 \pm 0.05$ & $0.85 \pm 0.04$ \\
\hline & $\dot{\varepsilon}, \mathrm{s}^{-1}$ & 0.0088 & 0.0088 & 0.0088 & 0.0088 \\
\hline \multirow{5}{*}{$\mathrm{D}$} & No of specimen & 3 & 3 & 3 & 3 \\
\hline & Average velocity, $\mathrm{m} / \mathrm{s}$ & 5.03 & 4.42 & 3.89 & 3.48 \\
\hline & $S_{E} A_{D}$ & $107.2 \pm 8.1$ & $64.7 \pm 4.5$ & $63.3 \pm 0.8$ & $48.1 \pm 2.3$ \\
\hline & $\mathrm{CFE}_{\mathrm{D}}$ & $0.82 \pm 0.01$ & $0.79 \pm 0.03$ & $0.82 \pm 0.00$ & $0.79 \pm 0.01$ \\
\hline & $\dot{\varepsilon}, \mathrm{s}^{-1}$ & 147.9 & 130.0 & 114.4 & 102.3 \\
\hline \multirow{4}{*}{ SHPB } & No of specimen & 3 & 3 & 3 & 3 \\
\hline & Average velocity, $\mathrm{m} / \mathrm{s}$ & 21.3 & 21.25 & 21.18 & 21.38 \\
\hline & SEA $_{S H P B}$ & $49 \pm 5$ & $38 \pm 3$ & $33 \pm 2$ & $33 \pm 3$ \\
\hline & $\dot{\varepsilon}, \mathrm{s}^{-1}$ & 1183.3 & 1180.5 & 1176.7 & 1187.8 \\
\hline
\end{tabular}


a)

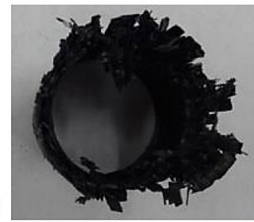

b)

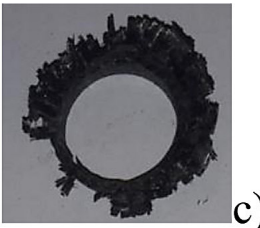

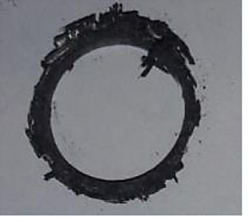

d)

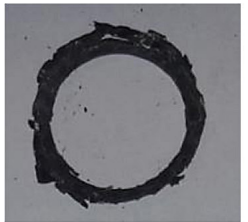

Fig. 14. View of representative crushed specimens; SHPB test; a) $\mathrm{AFMF}=1$; b) $\mathrm{AFMF}=0.8$; c) $\mathrm{AFMF}=0.6$; $) \mathrm{AFMF}=0.5$

- The results of the test showed that an increase in the share of axial fibers from $50 \%$ to $100 \%$ increases the amount of energy absorbed for the quasi static test by $85.4 \%$, for the dynamic test by $122.8 \%$ and for the test using SHPB by approximately $47.12 \%$.

\section{Acknowledgments}

The work was presented during the International Scientific Conference PRO-TECH-MA 2019, 15-17 September 2019, Herlany.

\section{REFERENCES}

1. Mazumdar S.K. Composites Manufacturing: Materials, Product, and Process Engineering. CRCPress, 2002.

2. Abosbaia A., Mahdi E., Hamouda A., Sahari B., Mokhtar A. Energy absorption capability of laterally loaded segmented composite tubes. Composite Structures, 70, 2005, 356-373.

3. Trzepiecinski T., Ryzinska G., Gromada M., Biglar M. 3D microstructure-based modelling of the deformation behaviour of ceramic matrix composites. Journal of The European Ceramic Society, 38 (8) 2018, 2911-2919

4. Trzepiecinski T., Ryzinska G., Biglar M., Gromada M. Modelling of multilayer actuator layers by homogenisation technique using Digimat software. Ceramics International, 43(3), 2017, 3259- 3266

5. Wu Yufeng, Yong Kim Gap. Fabrication of Al6061 composite with high $\mathrm{SiC}$ particle loading by semisolid powder processing. Acta Materialia, 58(13), 2010, 4398-4405

6. Alkbir M., Sapuan S., Nuraini A., Ishak M.. Fibre properties and crashworthiness parameters of natural fibre-reinforced composite structure: A literature review. Composite Structures, 148, 2016, 59-73.

7. Carruthers J., Kettle A. and Robinson A. Energy Absorption Capability and Crashworthiness of Composite Material Structures: A Review. Applied Mechanics Reviews, 51, 1998, 635-649.
8. Farley G.L. The effect of crushing speed on the energy - absorption capability of composite tubes. Journal of Composite Materials, 25, 1991, 1314-1329.

9. Ghasemnejad H., Hadavinia H., Aboutorabi A. Effect of delamination failure in crashworthiness analysis of hybrid composite box structures. Materials \& Design, 31, 2010, 1105-1116.

10. Hull D. A unified approach to progressive crushing of fibre-reinforced composite tubes. Composites Science and Technology, 40, 1991, 377-421.

11. Mahdi E., Hamouda A.M.S., Sen A.C. Quasi-static crushing of hybrid and nonhybrid natural fibre composite solid cones. Composite Structures, 66, 2004, 647-663

12. Oshkovr S.A., Eshkoora R.A., Taherb S.T., Ariffina A.K., Azhari C.H. Crashworthiness characteristics investigation of silk/epoxy composite square tubes. Composite Structures, 94, 2012, 2337-2342.

13. Yan L., Chouwa N., Jayaraman K. On Energy Absorption Capacity, Flexural and Dynamic Properties of Flax/Epoxy Composite Tubes. Fibers and Polymers, 15, 2014, 1270-1277.

14. Farley G.L., Jones R.M. Crushing characteristic of continuous fiber-reinforced composite tubes. Journal of Composite Materials, 26, 1992, 37-50.

15. Mahdi E., Sahari B., Hamouda A., Khalid Y. An experimental investigation into crushing behavior of filament-wound laminated cone-cone intersection composite shell. Composite Structures, 51, 2001, 211-219.

16. Mamalis A., Manolakos D., Ioannidis M., Papapostolou D. On the experimental investigation of crash energy absorption in laminate splaying collapse mode of FRP tubular components. Composite Structures, 70, 2005, 413-429.

17. Ramakrishna S., Hamada H., Maekawa Z. Energy absorption behavior of carbon fiber reinforced thermoplastic composite tubes. Journal of Thermoplastic Composite Materials, 14, 1995, 1121-1141.

18. Thornton P.H., Edward J. Energy Absorption in Composite Tubes. Journal of Composite Materials, 16, 1982, 521-545.

19. Carroll M., Ellyin F., Kujawski D., Chiu A.S. The rate-dependent behaviour of \pm 55 filament-wound 
glass fibre/epoxy tubes under biaxial loading. Composites Science and Technology, 55, 1995, 391-403.

20. Hou T., Pearce G.M.K., Prusty B.G., Kelly D.W., Thomson R.S. Pressurized composite tubes as variable load energy absorbers. Composite Structures, 120, 2015, 346-357.

21. Tao W., H., Robertson W., E., Thornton P.,H. Effects of material properties and crush conditions on the crush energy absorption of fiber composite rods. Composite Science and Technology, 47, 1993, 405-418

22. Mamalis A.G., Manolakos D.E., Ioannidis M.B., Papapostolou D.P. The static and dynamic axial collapse of CFRP square composite tubes, finite element modelling. Composite Structures, 74, 2006, 213-225.

23. Mamalis A.G., Robinson M., Manolakos D.E., Demosthenous G.A., Ioannidis M.B., Carruthers J. Crashworthy capability of composite material structures. Composite Structures, 37, 1997, 109-134.

24. Yang Y., Nakai A., Hamada H. A method to improve the energy absorption capability of fibre-reinforced composite tubes. International Journal of Crashworthiness, 14, 2009, 315-322.

25. David M., Johnson A., Voggenreiter H. Analysis of Crushing Response of Composite Crashworthy Structures. Applied Composite Materials, 20, 2013, 773-787.

26. Lavoie J.A., Kellas S. Dynamic crush tests of energy-absorbing laminated composite plates. Composites Part A, 27, 1996, 467-475.
27. Ryzińska G., David M., Prusty G., Tarasiuk J., Wroński S. Effect of fibre architecture on the specific energy absorption in carbon epoxy composite tubes under progressive crushing. Composite Structures, 227, 2019, 111292.

28. Mamalis A., Manolakos D., Demosthenous G., Ioannidis M., Analysis of failure mechanisms observed in axial collapse of thin-walled circural fiberglass composite tubes. Thin-Walled Structures, 24, 1996, 335-352.

29. Mamalis A.G., Manolakos D.E., Demosthenous G.A., Ioannidis M.B. The static and dynamic axial collapse of fibreglass composite automotive frame rails. Composite Structures, 34, 1996, 77-90.

30. Jackson A., Dutton S., Gunnion A., Kelly D. Investigation into laminate design of open carbon-fibre/ epoxy sections by quasi-static and dynamic crushing. Composite Structures, 93, 2011, 2646-2654.

31. Gupta N., Velmurugan R., Gupta S. An analysis of axial crushing of composite tubes. Journal of Composite Materials, 31, 1997, 1262-1286.

32. Ryzińska G., Gieleta R. Experimental studies on impact of CFRP tubes structure on amount of absorbed energy under dynamic conditions. Composites Theory and Practice, 4, 2018, 196-201.

33. Jacob G.C., Starbuck J.M., Fellers, J.F., Simunovic, S. Energy Absorption in Chopped Carbon Fiber Epoxy Composites for Automotive Crashworthiness. Polymer Journal, 35, 2003, 560-567.

34. Chen W., Song B. Split Hopkinson (Kolsky) Bar. Design, Testing and Applications. Springer, 2011.

35. Sharpe W.N., Springer Handbook of Experimental Solid Mechanics. Springer, 2008. 